\title{
DE LEGENDE VAN MANSREN MANGOENDI ${ }^{1}$
}

\author{
Door P. J. F. VAN HASSELT.
}

Onder den titel: de legende van Meok Woendi heeft het Encyclopaedisch Bureau in Aflevering II (1912) een gedeelte gepubliceerd van 't verslag van den Luitenant der Infanterie E. Tydeman, bevattende eene legende door dezen gehoord op Biak (Schouten-Eilanden), gedurende zijn verblijf aldaar in 1911.

Deze legende is niet nieuw. Als legende van Mangoendi is ze reeds ettelijke malen gepubliceerd, in de Berichten der Utrechtsche Zendingsvereeniging en in andere door deze Vereeniging uitgegeven werkjes.

Voor 't eerst is, naar ik meen, deze legende opgeteekend door den heer Fabritius, die als koopvaardijkapitein met zijn schoener "Fear not» de wateren van Papoea doorkruiste van 1850-1860. De heer Goudswaard publiceerde deze legende, na ze van den heer Fabritius vernomen te hebben, in zijn werkje: «De Papoewa's van de Geelvinksbaai» in 1863 te Schiedam uitgegeven.

Later publiceerde mijn vader ${ }^{2}$ de legende, o. m. in Deel XXXII (1889) van het Tijdschrift van het Bataviaasch Genootschap voor Kunsten en Wetenschappen, onder "Eenige aanteekeningen aangaande de bewoners der Noord-Westkust van Nieuw-Guinea , p. 266-268.

't Artikel van den heer Tydeman, zoowel als de andere publicaties van deze legende, zijn echter niet volledig. 'k Liet ze mij meermalen door verschillende personen uit verschillende streken vertellen, waardoor ik vollediger verhaal bekwam. 't

1 Manseren Mangoendi Manseren of Mansren is heer. 't Stamwoord Sren is als zoodanig niet meer in gebruik, wel als Sjen in het Windessisch. Man duidt aan 't mannelijk, in 't vrouwelijk. Manseren is dus heer, gebieder, en inseren is gebiedster.

Mangoendi is "hij zelf." Manseren Mangoendi is dus: de heer, hij zelf.

2 De Zendeling J. L. Van Hasselt. 
Encyclopaedisch Bureau vond de legende "wel waard om, met eenige daarmede samenhangende gebeurtenissen, in meer uitgebreiden kring bekend te worden»; waarom ik 't waag 't onderstaande ter lezing aan te bieden, dat wel niet op de verdienste boogt van nieuwigheid te zijn, maar toch aanspraak meent te mogen maken op grootere volledigheid.

Wie de zeekaart der Noordkust van Nieuw Guinea beziet, vindt $136^{\circ}-137^{\circ} \mathrm{O}$. L. en $1^{\circ}$ tot $1^{\circ} 20^{\prime} \mathrm{Z}$. Br. een groep eilanden, genaamd Padeaido Eilanden. Er staat een bijschrift bij: "Hier liggen waarschijnlijk nog meer eilanden " ${ }^{1}$ Een dergelijke noot op 'n zeekaart is zeker tegenwoordig wel iets zeldzaams.

't Aantal eilanden bedraagt $35 .^{2}$

De meeste zijn rotsachtig en stijgen hoog uit de zee op, enkele zijn zanderig en vlak. De zee is tusschen de eilanden in den regel ondiep.

't Aspect van de in de nabijheid liggende Schouten-Eilanden doet vermoeden, dat deze eenmaal een dergelijke eilandengroep vormden, die uit de zee opgeheven werd.

Één dezer Padeaido Eilanden ('k schrijf liever: Padèido) heet Meokwoendi. In April 1911 bezocht ik dit eilandje, waar nu slechts enkele huịzen staan van menschen, die belang hebben bij den klapper-aanplant op dit eiland, of die zich hier veilig denken voor den langen arm der Kompani. 't Eiland is klein, vlak en zanderig. Een tijd lang was het station voor de schepen der Kon. Paketvaart-Maatschappij. De Chineezen en Ternatanen, die hier dammer, copra en schelpen verhandelden, gevoelden zich op dit eilandje veiliger voor de toen, zeer terecht gevreesde Biakkers, dan op de vaste kust van Biak zelve.

1 Dit is de Zeekaart $n^{\circ} 155$, Schaal 1: 1.000.000, samengesteld te Batavia in 1889, uitgegeven te 's-Gravenhage in April 1900. De Zeekaart $\mathrm{n}^{\circ} 155$, zelfde schaal, samengesteld in 1912, uitgegeven te 's-Gravenhage in Nov. 1912 is reeds aanzienlijk beter, hoezeer nog onvolledig. Meokwoendi komt er op voor als: Mios Goendi.

RED.

${ }^{2}$ De eilanden dragen de volgende namen: Owi, Roerbas, Rawandi. A oeki, Mandi seroemi, Rarisbari, Meoswarki, Nioemeni, Oereb, Konoori, Meokwo endi, Noesi, Meosbaboi, Paï, Pakriki, Mbronsi, Padeiodidori, Jeri, Meos Mangwandi, Meoswark wondi, Samakoeri, Roeni, Sanfoeri, Noekori, Darvi, Dirwè, Rosi, Kebori, Pasi, Naïdi, Saboekanbondi, Oerbari, Wararasè, Adorifü.

De gespatieerde zijn alleen bewoond. 
Later werd 't station verplaatst naar Angeraï, in de nabijheid van Mokmer, de eenige eenigszins veilige reede op de Zuidkust van Biak.

Geen belangstelling echter voor den klapper-aanplant was het, die mij op Meokwondi bracht. Ik wenschte 't eiland te zien, dat door honderden Papoea's met zekeren eerbied genoemd werd.

Als bezienswaardigheden toonde men mij een betrekkelijk nog jongen klapperboom. Dit zou de boom zijn, waaruit Mangoendi zijn sagoweer tapte. Voorts een marěsboom ${ }^{1}$, die in den tijd van Mangoendi daar reeds zou gestaan hebben en een grooten zwarten steen, Mangoendi's slijpsteen. Een stuk van dien steen slaan, zou een orkaan verwekken. Ook werd de plek getoond, waar Mangoendi's huis zou gestaan hebben.

In overoude tijden woonde hier een oud, stokoud man. Zijn huid, van ouderdom gerimpeld, was bedekt met een uitslag die hem den bijnaam Manamakeri ${ }^{2}$ bezorgde.

Zijn hooge leeftijd belette hem echter niet zijn klapperboom te beklimmen om uit den bloemkolf sagoweer te tappen.

Op 'n morgen is zijne teleurstelling groot, als hij den bamboekoker ledig vindt. Blijkbaar is een dief hem vóúr geweest, die zich 't kostelijk vocht heeft toegeëigend. Den volgenden nacht blijft Mangoendi waken aan den voet van den boom. Hoe verbaasd was hij, toch den bamboekoker leeg te vinden. $\mathrm{Nu}$ besluit hij den volgenden nacht in den top van den boom door te brengen. Het gelukt hem den dief te vangen, 't is niemand meer en niemand minder dan Sampari, Venus, de Morgenster. ${ }^{3}$

1 De marĕs-boom (Mal. njamplong, Calophyllum Inophyllum L.) komt veel aan de kust voor. $\mathrm{Hij}$ maakt een prachtige bladerenkroon, bereikt een hoogen ouderdom. De bloesem is wit en welriekend, de vrucht kogelrond. De boom staat bij de Papoea's in zekere achting. Dikwijls heet hij de woonplaats van geesten te zijn en wordt dan gevreesd. Dan zal men den boom ongemoeid laten en hem geen tak ontrooven.

2 Manamakeri, Mandarmakeri, Mansarmakeri. Deze drie namen vindt men in de onderscheidene publicaties dezer legende. 't Grondwoord is maker, wat jeuken beteekent. Manamakeri is: de man, die jeuk heeft (door zijn huiduitslag). Mansarmakeri zou wezen: de grijsaard, die jeuk heeft. Mandar zou de zeldzame overgang van s. in d. vertoonen, die echter hier verklaard kan worden door den nevenvorm Mantar, wat groot beteekent.

3 Te Sor, noordkust van Biak werd me een klapperboom getoond, die niet mocht gekapt worden, want bij de wederkomst van Mangoendi zou de morgenster langs dien boom afdalen. 
Deze is natuurlijk zeer beschaamd, op heeter daad betrapt te zijn en smeekt om vrijgelaten te worden. Haar angst stijgt, als in 't oosten de wolken door haar purper de komst van de zon aankondigen. Want als de zon boven de kim verschijnt, dan zal ze vernietigd worden. Ze biedt Mangoendi aan een marěsvrucht en een gewoon stukje hout.

De marěsvrucht, geworpen op de borst van eene maagd, zal bij deze zwangerschap verwekken. Wat Mangoendi met 't stokje zal teekenen, zal hem in werkelijkheid geworden.

Een meisje, dat aan 't baden is, werpt hij met de marěsvrucht, en werkelijk na eenigen tijd blijkt 't meisje zwanger te zijn. Hare familie is niet weinig boos op haar, zij zelve niet weinig verbaasd. Op alle vragen moet ze 't antwoord schuldig blijven. Ze weet niet, wie de schuldige kan zijn, met niemand had ze gemeenschap.

Als eindelijk 't kind geboren is, dat Konori ' ${ }^{\prime}$ heet, moet deze zelf den vader aanwijzen.

Daartoe wordt een dans gëorganiseerd, waaraan alle mannen van 't eiland zullen deelnemen.

Eerst dansen de jongelingen langs 't kind heen. Maar 't kind zwijgt, daarna de pas gehuwde jonge mannen, voorts de mannen van middelbaren leeftijd, voorts de grijsaards; 't kind zwijgt. Eindelijk de twee of drie stokouden. En nu noemt Konori, Mangoendi als zijn vader.

Groote verbolgenheid van de zijde der bevolking, volgt op deze ontdekking. Men maakt de prauwen gereed om weg te varen. Alles wordt medegenomen, opdat Mangoendi, moeder en kind gebrek zullen lijden, want dezen worden niet medegenomen.

Als allen weg zijn, zegt de vrouw tot Mangoendi: «Gij hebt mij in groote moeilijkheid gebracht, hoe kom ik nu aan voedsel, gij zijt te oud om nog tuinen te ontginnen en prauwen te maken.

't Eenig antwoord van Mangoendi is: "Ga maar eens thuis kijken!» En daar ziet de vrouw tot hare groote verbazing een

1 Konoor. Zoo heeten de psendo-Mangoendi's ook. Er is hier dus verwisseling tusschen den nam van 't kind en den vader. Te Roon, Geelvinksbaai, noemt men ook de tooverdokters (sjaman) konoor. Deze heeten in de Doré-Baai : Mon. 
overvloed van uitgezochte spijzen. Mangoendi had de kracht beproefd van Sampari's tooverstokje.

Dit stokje toont ook zijne kracht, toen Mangoendi eene prauw noodig had om met vrouw en kind weg te reizen.

De Biakkers vertellen, dat hij met zijn stokje eene groote prauw en een groot aantal roeiers tooverde, met wie hij in de oneindige ruimte verdwijnt. De bewoners van 't kleine eiland Aoeki beroemen zich tot de familie van Mangoendi te behooren, waarom ze ook wel de Manamakeri of Mandarmakeri genoemd worden.

De Noemfooren echter, bewoners o. $m$ van de Doré-Baai, maken 'n ander slot aan 't verhaal, of liever voor hen begint 't belangrijkste. Als volgt:

Mangoendi met vrouw en kind voerèn in 'n klein vaartuig weg, naar het westen. Als kleine Konori vermoeid van het lange zitten in 't prauwtje, zijn verlangen te kennen gaf om een weinig te spelen, dan was 't voor Mangoendi eene kleinigheid om even 'n eilandje te tooveren. Aan die speelschigheid van Konori danken we de eilanden tusschen de Padeido-groep en Noemfor, b. v. Rani, en de eilanden voor Sowek en Noemfor zelve.

Hier was voorloopig 't einde van den tocht, want Mangoendi vestigde zich hier.

't Bleef Mangoendi niet verborgen, dat zijn oude schurftige huid zijne vrouw onaangenaam was. Op 'n dag maakt Mangoendi in 't bosch een groot vuur, en gaat er in staan. Zijn oude huid valt af en wordt veranderd in koperen borden. Hij treedt uit het vuur en spiegelt zich in 't water, dat in een groote schelp was. Toen hij zijn spiegelbeeld had beschouwd, vond hij de kleur van 't lichaam te licht. Nogmaals stapt hij in 't vuur. En als hij nu zich spiegelt in 't water van de schelp, vindt hij de kleur goed. Hij tooit zich met armbanden en andere versieringen, en wandelt naar huis. De vrouw is hoogst verbaasd een haar onbekend jongeling te zien naderen, en 't huis binnen treden. Ze roept hem toe, verre te blijven, want haar man is niet thuis en deze zou 't zeer kwalijk nemen een onbekende in zijne woning te zien. Mangoendi stelt haar gerust en zendt haar naar 't bosch om de koperen borden te halen. Als ze deze ziet en als ook Konori zijnen vader herkent, is ze verblijd over de verandering, die Mangoendi heeft ondergaan. 
Op den duur begint de eenzaamheid Mangoendi's vrouw te drukken. Ze verlangt naar meer menschen. Voor Mangoendi is de vervulling van dezen wensch natuurlijk maar kinderspel. Volgens sommigen doet 't tooverhoutje weer dienst; volgens anderen echter plant Mangoendi vier speren. Hoe 't ook zij, Mangoendi doet 4 huizen ontstaan met menschen.

Deze huizen zijn volgens de Noemfooren de vier hoofdfamiliën, waarin ze verdeeld zijn, n. l.: Roemberpon, Angradifoe, Roemansra en Roemberpoer.

Mangoendi was aller heer en hij zorgde als een vader voor de zijnen. Hij gaf hun te eten en genas de kranken.

Eens echter toen 't voedsel schaarsch was geworden, en een kind ernstig ziek was, begon men aan Mangoendi te twijfelen. Tot de moeder van ' $t$ kranke kind had M. gezegd: "Wees niet bang; als 't kind gestorven zal zijn, dan zal ik 't weer levend maken." Dit wekte den toorn der moeder, Infandwarndi, op; en ze uitte hare boosheid ondubbelzinnig in een echte Papoesche scheldpartij ann 't adres van Mangoendi, die op zijn beurt 't gebrek aan vertrouwen zeer euvel duidde en in een prauwtje wegtrok, Waarheen? Dat is niemand bekend. Maar Mangoendi komt terug, en dan begint voor de Papoea's de gouden tijd, de tijd, waarin volgens den Noemfor niemand meer behoeft te werken, en 't voedsel overvloedig is. '

De Biakker echter heeft nog meerdere verwachting van Mangoendi's terugkomst. Dan zal het tijdperk der Koreri aanbreken. Dit Koreri is afgeleid van 't grondwoord rer, een Biaksch woord, dat beteekent: "van huid verwisselen» z. a. b. v. geschiedt met slangen en kreeften. Wanneer de Koreri aanbreekt, dan zullen de kranken gezond worden, de menschen behept met wonden. zullen een feilloos lichaam krijgen, dooden zullen levend worden en levenden zullen niet meer sterven.

't Geloof van den Noemfoor in Mangoendi's wederkomst en in den toekomstigen heilstaat der Noemfooren is zeer verzwakt, maar niet geheel dood. De Biakker gelooft met zijn geheele

\footnotetext{
1 Op Noemfoor zegt men, kan men nog de uitgedoofde sintels zien van't vuur, waarin Mangoendi zich verbrandde, en de schelp, waarin hij zich spiegelde. Ik liet mij deze souveniers wijzen. 't Was echter niet veel bijzonders. Nog wees men mij een doorboorden steen; dat zou Mangoendi's geweer zijn geweest en een grooten steen in zee, dat zon Mangoendi's anker zịjn.
} 
hart aan deze dingen, die hem van de vaderen zijn overgeleverd.

En met dit geloof, hangen sommige gebeurtenissen samen, waarvan een enkele door het rapport Tydeman vermeld wordt, in de publicatie van 't Encyclopaedisch bureau.

Zoo nu en dan trad iemand op met de bewering Mansren Mangoendi te zijn of althans door hem te zijn gezonden. Groote bekendheid verwierf zich de tegenwoordige Korano van Mokmer, die in 1884 tot 1886 van zich deed hooren. Dat hij de eerste was, die met de praetentie optrad Mangoendi te zijn (rapportTydeman), is minder juist. Maar 't gelukte hem zich vermaard te maken, verre buiten zijne omgeving.

Zendeling Jens $\mathrm{S}^{r}$. meldde, dat zijne woonplaats Kwawi werd bezocht door afgezanten van een z.g. n. groot wonderdoener Mangoendi geheeten, die de bevolking aldaar door de verhalen van allerlei wonderen, die deze Konoor deed, trachtte te bewegen hem te eeren en schatting te betalen.

Mijn vader meldde o. m: 't Gerucht zegt, dat hij rijksdaalders en blauw katoen uit zee opvischt; een eindje sigaar in een geweer, en boombladeren in visschen verandert; grijsaards verjongt, voor een oud gebit een nieuw geeft, grijze haren in zwart verandert (l. c. p. 265-266).

Voor eenige jaren was er zoodanig een Konoor op Wandammen, 's mans heerlijkheid is uitgegaan als een nachtkaars, desniettemin loopen zij elken nieuwen bedrieger na.

Van eene andere zijde vernam ik, dat de Konoor last gegeven had, dat ze maar goed moesten zingen, dan zouden ze, als ze over vier maanden terugkeerden, deelen in al de voorrechten, die zijnen vereerders te beurt vielen.

Zendeling Van Balen meldde (Ber. U.Z.V. 1886, bl. 66): "Tot wel verstand, dien ik thans mede te deelen, dat in het begin dezes jaars op Meokwondi, een der Biaksche eilanden, zich weder een Konoor heeft opgeworpen, die vertelde, dat eerlang door zijn toedoen een groot stoomschip met allerlei goederen voor hen zou aankomen, en dat ieder, die van de gelegenheid wilde profiteeren, nu maar bij hem goederen moest komen offeren. Kapt. Amos (een Ternataan, die als schoenerkapitein Nieuw Guinea meermalen bezocht) vertelde ons dit op Mansenam en zeide, dat Meokwondi toen vol volks was, van allerlei stammen, z. a. Ansoesers, Wandammers, Windessiërs, 
Rhooners, Waropeners enz. Terwijl wij hier zijn, zijn er dan ook twee prauwen van hier terug gekomen, doch wij konden van hen niets te weten komen.»

En in de Berichten der U. Z. V. 1887 blz. 52 van de hand mijns vaders 't volgende, naar aanleiding van den moord op Kapitein Holland, gezagvoerder van de Corredo, stoomscheepje der N. G. Handel Maatschappij: "Intusschen geloof ik wel, dat afgezien van den woesten aard der bevolking zij opgestookt is. Die opstoker is niemand anders dan de Konoor. Deze leugenprofeet wil gaarne den schijn aannemen, alsof hij ook de blanken overvleugelt; het oproer van voor 2 jaren, waarbij ik ter nauwernood een speerstoot ontkomen ben, was, althans zijdelings zijn werk. De bevolking was in eene opgewondene, ons vijandige stemming. De Konoor had bevolen, dat zij moesten zingen, veel zingen; dat deden ze dan ook; onder anderen was de inhoud van een hunner liedjes: "We willen wel bij je komen, maar kunnen niet, de vreemde Hollandsche vogels sluiten de deur toe," terwijls dat ze telkens, dan die en dan die troep, naar hun beroemden "heer» gingen. Dat we op de Amberno ' op een bank zijn gekomen, is naar hij voorgeeft, zijn werk, "hij heeft het water droog gemaakt,» enz.

In het «Rapport van eene reis naar de Noordkust van NieuwGuinea» door den toenmaligen controleur (later resident van Ternate) Dr. D. W. Horst, deelt deze mede: „dat twee maanden geleden al de negorijen van het exland Koeroedoe door eene vloot van 10 prauwen, bestaande uit Koridanen, Sowekers en Brakers, onder aanvoering van de Sengadjis van Korido en Sowek, den Konor van Sapoor en den Sengadji van Bosnek waren overvallen en gedeeltelijk verbrand. Daarbij waren twee dooden gevallen aan den kant van Koeroedoe, en 20 menschen slaven gemaakt.»

De toenmalige Konoor, aanvoerder van sneltochten, is er maar al te goed afgekomen. De toenmalige resident, De Clercq, heeft hem tot hoofd aangesteld. Hij leeft nog, maar zijn invloed is niet meer van groote beteekenis. Zijn zoon, de Kapitein-laut Amas, heeft de leiding genomen. De regeering moest hem

1 Bedoeld wordt de stranding van de Havik op Havik-eiland in de Mamberamoe, d.d. 22 Juli 1884 (verg. deze Bịdragen, $4^{\circ}$ Reeks, X, 1885, p. $104-105)$.

Dl, 69 
onlangs doen gevoelen dat de oude tijden van geweldenarij voorbij moesten zijn. Hij had eene vrouw van Sowek met een geweerkolf dermate bewerkt, dat het schouderblad gebroken was, en dat om een quaestie, die hij met Sowekkers had.

'n Ander Konoor herinner ik me van 1901. Deze zond den controleur, nu ass. res. Van Oosterzee te Manokwari twee geel geworden marěs-bladeren. Op die bladeren stonden poppetjes geteekend. De brengers verklaarden den heer Van Oosterzee, dat er op hun eiland Noemfoor iemand verschenen was, die per prauw noch per schip er gekomen was; en deze had hun gelast die "toeras" (soerat $=$ brief) aan zijn zoon te Manokwari te brengen. Deze zou wel weten, wat er op stond.

Van Biakkers vernam ik, dat deze Konoor, een grooten ijzerhoutboom uit den grond had gerukt, dat hij dooden levend maakte enz. dat hij ook gezegd had: "Zoodra mijn zoon te Manokwari deze "toeras» leest, dan komt hij mij zien:» Ik deelde dit den heer v. Oosterzee mee, die toen zijn oorspronkelijk plan opgaf, om naar Noemfoor te gaan.

Niet lang daarna kwam de Konoor in een met vlaggen versierde prauw zijn "zoon» een bezoek brengen. 't Eiland Mansinam voer hij goedgunstig voorbij, want als hij dat betrad zou 't eiland verzinken.

De wijze van optreden van dezen Konoor deed den heer van Oosterzee besluiten hem in de boeien te laten sluiten. ' $k$ Heb hem bezocht. Hij leek mij aan auto-suggestie te lijden. Hij hield vol uit den hemel te zijn neergedaald. Den man werd spoedig zijne vrijheid hergeven; zijn invloed was echter gebroken. 't Was iemand die op Noemfoor thuis hoorde, er niet sper prauw noch per schip gekomen was, m maar er geboren werd.

Langen tijd hoorden we niet van 't optreden van nieuwe Konoors, tot in 1910 de Mamberamoe door een exploratiedetachement onder kapitein Franssen Herderschée werd bezocht. De Papoea's gingen zich natuurlijk afvragen: "Wat doen de Hollanders nu daar?» Eenigen waren heel gaauw klaar met het antwoord en zeiden: "Wel, ze zoeken goud, 't begin en 't eind van den handel." De Biakkers philosopheerden echter, dat 't om Mangoendi en de Kareri te doen was. Met hunne meerclere middelen waren de Hollanders er in geslaagd te weten te komen, dat Mangoendi zich aan de Mamberamoe ophield.

Deze gedachte werd zeer gepropageerd door zekeren Mangi- 
nòmi, die een Papoesche expeditie op touw zette naar de Mamberemoe. Aan die tocht werd o. m. deelgenomen door den kapitein-laut Amas van Mokmer, zoon van den beruchten Korano.

Het exploratie-detachement was door beri-beri genoodzaakt geworden "huis-toe» te gaan. Men vond er echter den Duitscher Dr. Moszkowski. Verscheidene deelnemers der expeditie vroeg $i k$, of ze Mangoendi gezien hadden? "Neen, men had geen Mangoendi gezien, alleen hadden ze er een Ingris ' ${ }^{1}$ gevonden. Alleen Manginomi was gelukkiger geweest. Mangoendi was hem verschenen en had hem gelast zijn komst op Noemfoor voor te bereiden. Hij beschreef Mangoendi als een reus, die ontzaglijk eten kon. Te Bawe op Noemfoor zou Mangoendi zijnen getrouwen verschijnen. Eene groote woning werd gebouwd. Naar her en der stuurde Manginomi boodschappers. Als er zóo en zóo veel stukken blauw katoen, zóo en zóo veel vrouwen enz. enz. waren dan zou Mangoendi komen.

't Huis was in twee deelen gescheiden. In 't éene deel mocht het publiek niet komen. Daar verschenen volgens 't zeggen de radja's van Tidore, Djailolo en Ternate, ja ook de radja van Holland; allen om de komst van den radja Papoea aan te kondigen.

'k Vroeg verlof zoo'n voorstelling te mogen bijwonen, wat mij niet toegestaan werd. De houding van een gedeelte der bevolking was niet welwillend Manginomi was gansch niiet te spreken over de goeroe's, mijne onderwijzers, die hunne dorpen tegen den bedrieger waarschuwden, waardoor hem minder toevloeide, dan anders 't geval zou geweest zijn. "Maar, wacht, " was zijn dreigement, "als ik mijn medicijn te vuur zet, dan zal dit de onwilligen bespatten, dat ze sterven.» Handtastelijk trad hij zelfs tegen een der goeroe's op.

Als de spanning van de bevolking 't hoogst is, als 't publiek gaat vragen om vervulling der beloften, dan wordt zoo'n Konoor gevaarlijk; dan is b.v. een uitspraak als: "Mangoendi komt niet, zoolang er vreemdelingen op 't eiland zijn,» voldoende om de bevolking daadwerkelijk te doen optreden.

Zóóver is 't niet gekomen. Gelijk 't rapport-Tydeman meldt,

1 Wat geen Hollander en toch blank is, wordt door de Papoea's Ingris (Engelschman) genoemd. 
werd Manginomi gevangen genomen en naar Ternate verbannen.

't Een en ander toont aan, hoe vast echter de Poepoea's gelooven in hetgeen hun van de vaderen is overgeleverd.

Manokwari. (N. Nieuw-Guinea), 1913. 